\title{
Quinaprilat during cardioplegic arrest in the rabbit to prevent ischemia-reperfusion injury
}

Peter Korn, MD, ${ }^{a}$ Andreas Kröner, MD, ${ }^{\mathrm{b}}$ Jan Schirnhofer, MD, ${ }^{\mathrm{b}}$ Seth Hallström, PhD, ${ }^{\mathrm{b}}$ Oliver Bernecker, MD, ${ }^{\mathrm{a}}$ Rudolf Mallinger, MD, ${ }^{\mathrm{c}}$ Maximilian Franz, BS, ${ }^{\mathrm{a}}$ Harald Gasser, BS, ${ }^{\mathrm{b}}$ Ernst Wolner, MD, ${ }^{\mathrm{a}}$ and Bruno K. Podesser, MD ${ }^{\mathrm{a}}$

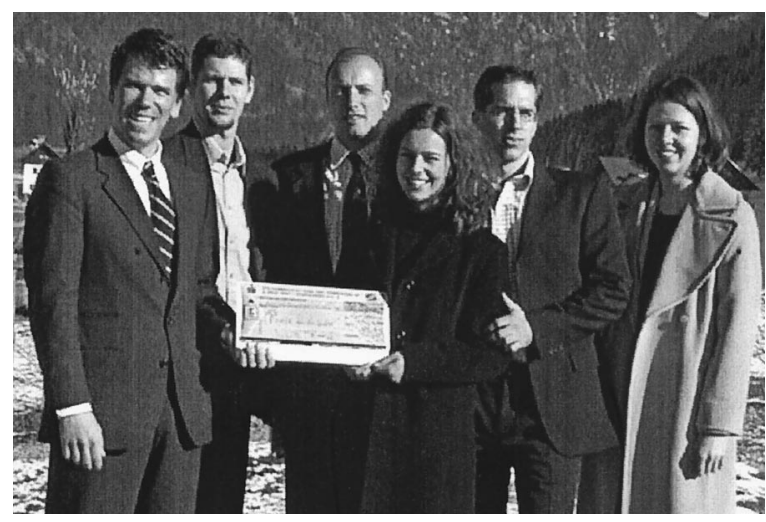

Semsroth and Fellner (row 1); Bernecker, Podesser, Franz, and Trescher (row 2); Korn (missing; presently at Cornell University)
Objectives: This study evaluated intracardiac angiotensin-converting enzyme inhibition as an adjuvant to cardioplegia and examined its effects on hemodynamic, metabolic, and ultrastructural postischemic outcomes.

Methods: The experiments were performed with an isolated, erythrocyte-perfused, rabbit working-heart model. The hearts excised from 29 adult New Zealand White rabbits $(2950 \pm 200 \mathrm{~g})$ were randomly assigned to four groups. Two groups received quinaprilat $(1 \mu \mathrm{g} / \mathrm{mL})$, initiated either with cardioplegia $(\mathrm{n}=7)$ or during reperfusion $(n=7)$. The third group received L-arginine (2 $\mathrm{mmol} / \mathrm{L})$ initiated with cardioplegia $(\mathrm{n}=7)$. Eight hearts served as a control group. Forty minutes of preischemic perfusion were followed by 60 minutes of hypothermic arrest and 40 minutes of reperfusion.
From the Department of Cardiothoracic Surgery, AKH Wien, Vienna ${ }^{\mathrm{a}}$; the Ludwig Boltzmann Institute for Heart Research, Vienna ${ }^{\text {b; }}$ and the Department of Histology and Embryology II, University of Vienna, Austria. ${ }^{\mathrm{c}}$

Supported by funds from the Ludwig Boltzmann Institute for Heart Research and Hans und Blanca Moser Stiftung, both in Vienna, Austria. Quinaprilat was generously provided by Dr R. Bakovic-Alt, Gödecke AG, Freiburg, Germany. Statistical analysis was conducted in cooperation with Meinhard Ploner, PhD, Department of Cardiothoracic Surgery, AKH Wien, Vienna, Austria.

Received for publication Jan 26, 2000; revisions requested Feb 23, 2000; revisions received Oct 19, 2001; accepted for publication Oct 24, 2001.

Address for reprints: Bruno K. Podesser, MD, Associate Professor of Cardiac Surgery, Ludwig Boltzmann Institute for Cardiosurgical Research, c/o Institute of Biomedical Research, Allgemeines Krankenhaus Wien, Waehringer Guertel 18-20, 1090 Vienna, Austria (E-mail: B.K.Podesser@ cardiovascular-research.at). J Thorac Cardiovasc Surg 2002;124:352-60 Copyright () 2002 by The American Association for Thoracic Surgery

$0022-5223 / 2002 \$ 35.00+0 \quad \mathbf{1 2 / 1 / 1 2 1 6 7 6}$

doi: $10.1067 / \mathrm{mtc} .2002 .121676$
Results: All treatments substantially improved postischemic recovery of external heart work $(62 \% \pm 6 \%, 69 \% \pm 3 \%$, and $64 \% \pm 5 \%$ in quinaprilat during cardioplegia, quinaprilat during reperfusion, and L-arginine groups, respectively, vs $35 \% \pm 5 \%$ in control group, $P<.001)$ with similarly increased external stroke work and cardiac output. When administered during ischemia, quinaprilat significantly improved recovery of coronary flow $(70 \% \pm 8 \%, P=.028$ vs quinaprilat during reperfusion $[49 \% \pm 5 \%]$ and $P=.023$ vs control $[48 \% \pm 6 \%]$ ). L-Arginine $(55 \% \pm 7 \%)$ showed no significant effect. Postischemic myocardial oxygen consumption remained low in treatment groups $\left(4.6 \pm 1.2 \mathrm{~mL} \cdot \mathrm{min}^{-1} \cdot 100 \mathrm{~g}^{-1}, 6.0 \pm\right.$ $2.2 \mathrm{~mL} \cdot \min ^{-1} \cdot 100 \mathrm{~g}^{-1}$, and $4.7 \pm 1.6 \mathrm{~mL} \cdot \min ^{-1} \cdot 100 \mathrm{~g}^{-1}$ in quinaprilat during cardioplegia, quinaprilat during reperfusion, and L-arginine groups, respectively, vs $4.2 \pm 0.8 \mathrm{~mL} \cdot \mathrm{min}^{-1} \cdot 100 \mathrm{~g}^{-1}$ in control group), even though cardiac work was markedly increased. High-energy phosphates, which were consistently elevated in all treatment groups, showed a significant increase in adenosine triphosphate with quinaprilat during ischemia $(2.24 \pm 0.14 \mu \mathrm{mol} / \mathrm{g}$ vs $1.81 \pm 0.12 \mu \mathrm{mol} / \mathrm{g}$ in control group, $P=.040)$. Ultrastructural grading of mitochondrial damage revealed best preservation with quinaprilat during ischemia (100\% [no damage], $P=.001$ vs control).

Conclusion: These experimental findings have clinical relevance regarding prevention of postoperative myocardial stunning and low coronary reflow in patients undergoing heart surgery.

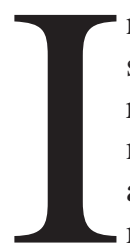

$n$ recent years angiotensin-converting enzyme (ACE) inhibitors have been shown to exert a protective effect in various settings of acute ischemia and reperfusion. ${ }^{1-3}$ Most evidence suggests that increased synthesis of nitric oxide, mediated through accumulated bradykinin, plays a pivotal role in protection against ischemia-reperfusion injury. ${ }^{3-5}$ The tissue activities of these paracrine mediators thus are increased by inhibition of intracardiac ACE and kininase II, accounting for the reproducibility of cardioprotective effects at the organ level.

Acute postischemic administration of ACE inhibitors has shown some clinical benefits for cardiac protection in such settings as thrombolysis ${ }^{6}$ or the acute phase 


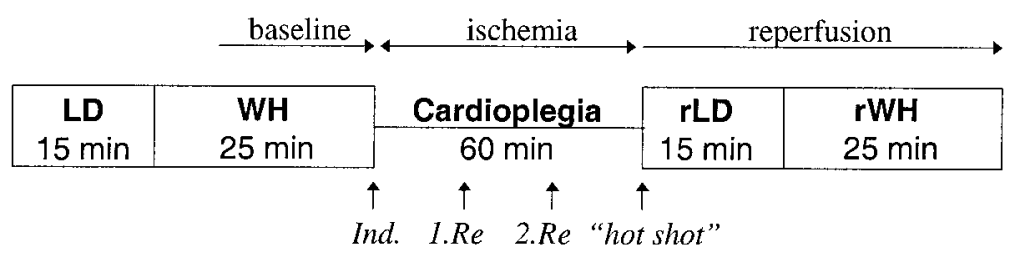

IQ: quinaprilat $(1 \mu \mathrm{g} / \mathrm{ml})$

ARG: L-arginine ( 2 mmoll $)$

PQ: quinaprilat $(1 \mu \mathrm{g} / \mathrm{ml})$

Figure 1. Experimental protocol. Drugs were admixed with blood fractions of respective cardioplegic infusions and with perfusates of subsequent reperfusion. $L D$, Preischemic Langendorff mode; WH, preischemic working-heart mode; $r L D$, Langendorff mode during reperfusion; $r W H$, working-heart mode during reperfusion; Ind, induction of cardioplegia; $R e$, reinfusion; $I Q$, ischemia quinaprilat group; $A R G$, arginine group; $P Q$, reperfusion quinaprilat group.

of myocardial infarction. ${ }^{7-9}$ The application of these drugs during induced cardiac arrest would allow even earlier initiation of ACE inhibition, concurrent with the ischemic event. Cardioplegic solutions thus constitute an ideal vehicle for the introduction of agents aiming to improve myocardial and vascular protection during ischemia and reperfusion. ACE inhibitors might be an attractive adjuvant in this setting. As opposed to standard cardioplegic solutions, their cardioprotective mechanisms involve modification of endogenous mediators to support the heart's own defense against ischemia. Furthermore these mediators may help to preserve endothelial function. However, the reduced metabolic activity during hypothermia may limit such an endogenous protection, and data about the efficacy of ACE inhibition during cold blood cardioplegia are still sparse. ${ }^{10-12}$ The rationale for clinical application remains unsettled.

This study evaluated the acute inhibition of intracardiac ACE by means of quinaprilat as adjuvant to cold blood cardioplegia. Hemodynamic, metabolic, and ultrastructural postischemic outcomes in the isolated erythrocyte-perfused working heart were analyzed. Quinaprilat initiated during cardioplegia was compared with administration during reperfusion only to investigate the influence of timing. LArginine initiated during cardioplegia provided comparison with an alternative treatment option of clinical significance and served as a positive control with respect to the putative role of nitric oxide as mediator during ACE inhibition.

\section{Methods}

\section{Experimental Design}

The study was performed as a randomized experimental trial with an isolated, erythrocyte-perfused, rabbit working-heart model (Hugo Sachs Elektronik, Freiburg, Germany) that has been described in detail in previous publications by Podesser and colleagues. ${ }^{13,14}$ The perfusate consisted of a Krebs-Henseleit bufferbased suspension of purified bovine erythrocytes (hematocrit 30\%) oxygenated with low gas $(75 \%$ nitrogen $/ 20 \%$ oxygen/5\% carbon dioxide) to provide a constant $\mathrm{Po}_{2}$ of $100 \pm 10 \mathrm{~mm} \mathrm{Hg}$. Compo- sition of the buffer was as follows: $118-\mathrm{mmol} / \mathrm{L}$ sodium chloride, 4.7- $\mathrm{mmol} / \mathrm{L}$ potassium chloride, $2.5-\mathrm{mmol} / \mathrm{L}$ calcium chloride, $1.2-\mathrm{mmol} / \mathrm{L}$ magnesium sulfate, $1.2-\mathrm{mmol} / \mathrm{L}$ potassium dihydrogen phosphate, $0.5-\mathrm{mmol} / \mathrm{L}$ sodium ethylenediaminetetraacetate, $25-\mathrm{mmol} / \mathrm{L}$ sodium hydrogen carbonate, $11.1-\mathrm{mmol} / \mathrm{L}$ glucose, 2.5-IU/L insulin, and $0.2-\mathrm{g} / \mathrm{dL}$ bovine albumin.

The hearts excised from 29 adult New Zealand White rabbits, weighing $2950 \pm 200 \mathrm{~g}$, were randomly assigned to four groups. Two groups received $0.3 \mathrm{mg}$ quinaprilat $(1 \mu \mathrm{g} / \mathrm{mL})$, initiated either during ischemia with the first cardioplegic reinfusion (ischemia quinaprilat group, $\mathrm{n}=7$ ) or during reperfusion with the hot shot (reperfusion quinaprilat group, $\mathrm{n}=7$ ). The third group received $120 \mathrm{mg}$ L-arginine $(2 \mathrm{mmol} / \mathrm{L})$ initiated with the first cardioplegic reinfusion, in parallel with the ischemia quinaprilat group (arginine group, $\mathrm{n}=7$ ), and 8 hearts served as a control group. For the purpose of randomization the assignment of animals was subject to chance, and all experiments were conducted in a randomly chosen order. A preischemic aortic flow of less than $250 \mathrm{~mL} / \mathrm{min}$ served as an exclusion criterion.

The perfusion was conducted according to a standardized protocol, which is depicted in Figure 1. The Langendorff mode provided constant pressure coronary perfusion at $70 \mathrm{~mm} \mathrm{Hg}$. In the subsequent preischemic working-heart mode, after left atrial loading (mean atrial pressure of $5 \mathrm{~mm} \mathrm{Hg}$ ), the left ventricle ejected the perfusate against a predefined afterload, giving rise to $70 \mathrm{~mm} \mathrm{Hg}$ mean aortic pressure. Decreasing cardiac output was accompanied by slight elevation of atrial pressure and decline in aortic pressure, thus mimicking clinical conditions. Hearts were beating spontaneously at a mean rate of $3 \mathrm{~Hz}$ throughout the perfusion. The cardioplegia was performed as multidose cold blood cardioplegia according to Buckberg (Buckberg Kardioplegie; Köhler Chemie GmbH, Koblenz, Germany) at a 4:1 ratio of perfusate to Buckberg solution, administered at $8^{\circ} \mathrm{C}$ with a constant pressure of $50 \mathrm{~mm}$ Hg. During ischemia, after the heart had been arrested with the first cardioplegic infusion (induction), drugs were added to the pool of perfusate, which then provided the blood fraction for subsequent cardioplegic reinfusions. This guaranteed precise dosage of drugs in small volumes (cardioplegia) and provided adequate concentrations at the time of reperfusion. Quinaprilat for the ischemia quinaprilat group and L-arginine for the arginine group were added 
before the first reinfusion. Quinaprilat for the reperfusion quinaprilat group was added before the hot shot that initiated the reperfusion (Figure 1).

\section{Drugs \\ Quinaprilat (Gö 9018-1; Gödecke AG, Freiburg, Germany) is a parenterally applicable carboxyl-type ACE inhibitor. Even though its initial elimination half-life in plasma is short (2 hours), quinaprilat has a prolonged terminal half-life of 25 hours, which corresponds to its pharmacologic activity. ${ }^{15,16}$ This phenomenon is explained by its high-affinity binding to tissue ACE with consec- utive slow dissociation. ${ }^{15}$ L-Arginine (Merck 1.01542; Merck AG, Darmstadt, Germany) constitutes the physiologic substrate for all types of nitric oxide synthases. Its pharmacologic effects are thought to be mediated exclusively by its ability to increase the synthesis of nitric oxide.}

\section{Hemodynamic Data Acquisition}

The myocardial function was assessed by cardiac output (identical to the left atrial flow in a closed system), the external heart work (cardiac output times mean aortic pressure, indicating the pressurevolume work performed per minute), and the external stroke work (cardiac output times mean aortic pressure divided by heart rate, the most accurate indicator of myocardial function in this model). The external heart work was expressed in grams per meter per minute (the value in milliliters per minute per millimeter of mercury multiplied by 0.0136 ) and referenced to the heart weight. The coronary flow was calculated by subtracting aortic flow from left atrial flow. The hemodynamic baseline was defined as the mean obtained from readings at 10, 15, and 25 minutes during the preischemic working-heart mode, when stable conditions were achieved. To adjust for minor deviations in baseline hemodynamics, readings from the reperfusion period were expressed as recovery (percentage of baseline). The mean recovery encompassed all time points of the working-heart period during reperfusion.

\section{Biochemical Evaluation}

An arterial and coronary venous blood gas analysis performed in each working-heart period (after 10 minutes in preischemic workingheart mode and working-heart mode during reperfusion) allowed the calculation of the myocardial oxygen consumption according to the Fick law (oxygen consumption $=$ arterial-venous oxygen saturation difference $\times$ hemoglobin concentration $\times 1.34 \mathrm{~mL}$. $\mathrm{g}^{-1} \times$ coronary flow $\times$ heart weight ${ }^{-1}$ ). For estimation of nitric oxide synthesis, nitrite and nitrate levels were measured at baseline (after 10 minutes in preischemic working-heart mode) and during reperfusion $(5,15$, and 25 minutes during working-heart mode during reperfusion). Two milliliters of perfusate drawn from the venous effluent was centrifuged, and the supernatant was stored at $-80^{\circ} \mathrm{C}$. Then protein precipitation with acetonitrile was performed with the postcolumn derivatization technique, as described by Green and associates. ${ }^{17}$ A cadmium/copper column was inserted into the high-performance liquid chromatographic system after the gel permeation column for reduction of nitrate to nitrite. For analysis of high-energy phosphates, freeze-clamped biopsy samples were taken from the apical myocardium at the end of the reperfusion and stored in liquid nitrogen. Concentrations of adenine nucleotides (adenosine triphosphate [ATP], adenosine diphos- phate, and adenosine monophosphate) and creatine phosphate (CP) were determined by high-performance liquid chromatography according to the method of Fürst and Hallström ${ }^{18}$ and expressed in micromoles per gram wet weight.

\section{Ultrastructural Evaluation}

Two myocardial specimens were harvested from the septal and external portions of the left ventricular wall and fixed with $4 \%$ paraformaldehyde and $1 \%$ glutaraldehyde in $0.1-\mathrm{mol} / \mathrm{L}$ cacodylate buffer. Histologic processing was performed according to standard methods. Transmission electron microscopy (JEM-1200 EX; JEOL Ltd, Akishima, Japan) at a magnification of $\times 45,000$ (3 microscopic fields for each heart) was used to determine mitochondrial damage. This evaluation was conducted independently by two histologists who were blinded to sample origins. Mitochondrial damage was graded according to the following semiquantitative scheme ${ }^{19}$ : grade 0 , no visible damage, normal matrix granules; grade 1, loss of matrix granules and light clearing of matrix; grade 2, moderate clearing of matrix, moderate swelling, and partial fragmentation of cristae; grade 3, severe clearing, severe swelling, and loss of cristae; and grade $3 \mathrm{a}$, amorphous dense granules. Each individual heart was assigned an overall grade for mitochondrial damage, which was derived as the mean of the three microscopic fields.

\section{Animal Care}

This study was approved by the ethical committee of the University of Vienna and by the Ministry of Science, Republic of Austria. Care of animals was in accordance with the "Guide for the Care and Use of Laboratory Animals" prepared by the Institute of Laboratory Animal Resources, National Research Council, and published by the National Academy Press, revised 1996.

\section{Statistical Analysis}

All parametric data were referenced to the heart weight (as measured before perfusion) and expressed as mean \pm SEM. Analysis of variance (ANOVA) and analysis of covariance were performed with the SPSS 8.0 software package (SPSS Inc, Chicago, Ill). Statistical significant results were specified post hoc with the Fisher least significant difference test. Ordinal parameters (ultrastructural grading) were transformed for ANOVA by the Fechner marginal normalization.

\section{Results}

\section{Hemodynamic Data}

Baseline hemodynamics demonstrated comparable preischemic conditions without significant differences (external heart work in ischemia quinaprilat group $29.3 \pm 2.4[\mathrm{~g} \cdot \mathrm{m}$ $\left.\cdot \min ^{-1}\right] \cdot \mathrm{g}^{-1}$, reperfusion quinaprilat group $29.0 \pm 2.5[\mathrm{~g}$ $\left.\cdot \mathrm{m} \cdot \min ^{-1}\right] \cdot \mathrm{g}^{-1}$, arginine group $31.2 \pm 2.9\left[\mathrm{~g} \cdot \mathrm{m} \cdot \mathrm{min}^{-1}\right]$ $\cdot \mathrm{g}^{-1}$, and control group $30.0 \pm 1.8\left[\mathrm{~g} \cdot \mathrm{m} \cdot \mathrm{min}^{-1}\right] \cdot \mathrm{g}^{-1}$; coronary flows in ischemia quinaprilat group $2.7 \pm 0.5 \mathrm{~mL}$ $\cdot \min ^{-1} \cdot \mathrm{g}^{-1}$, reperfusion quinaprilat group $3.2 \pm 0.5 \mathrm{~mL}$ $\cdot \min ^{-1} \cdot \mathrm{g}^{-1}$, arginine group $2.5 \pm 0.4 \mathrm{~mL} \cdot \min ^{-1} \cdot \mathrm{g}^{-1}$, and control group $\left.2.8 \pm 0.3 \mathrm{~mL} \cdot \mathrm{min}^{-1} \cdot \mathrm{g}^{-1}, P>.2\right)$. The spontaneous heart rate showed only minor variability among groups. During reperfusion, all hearts promptly re- 

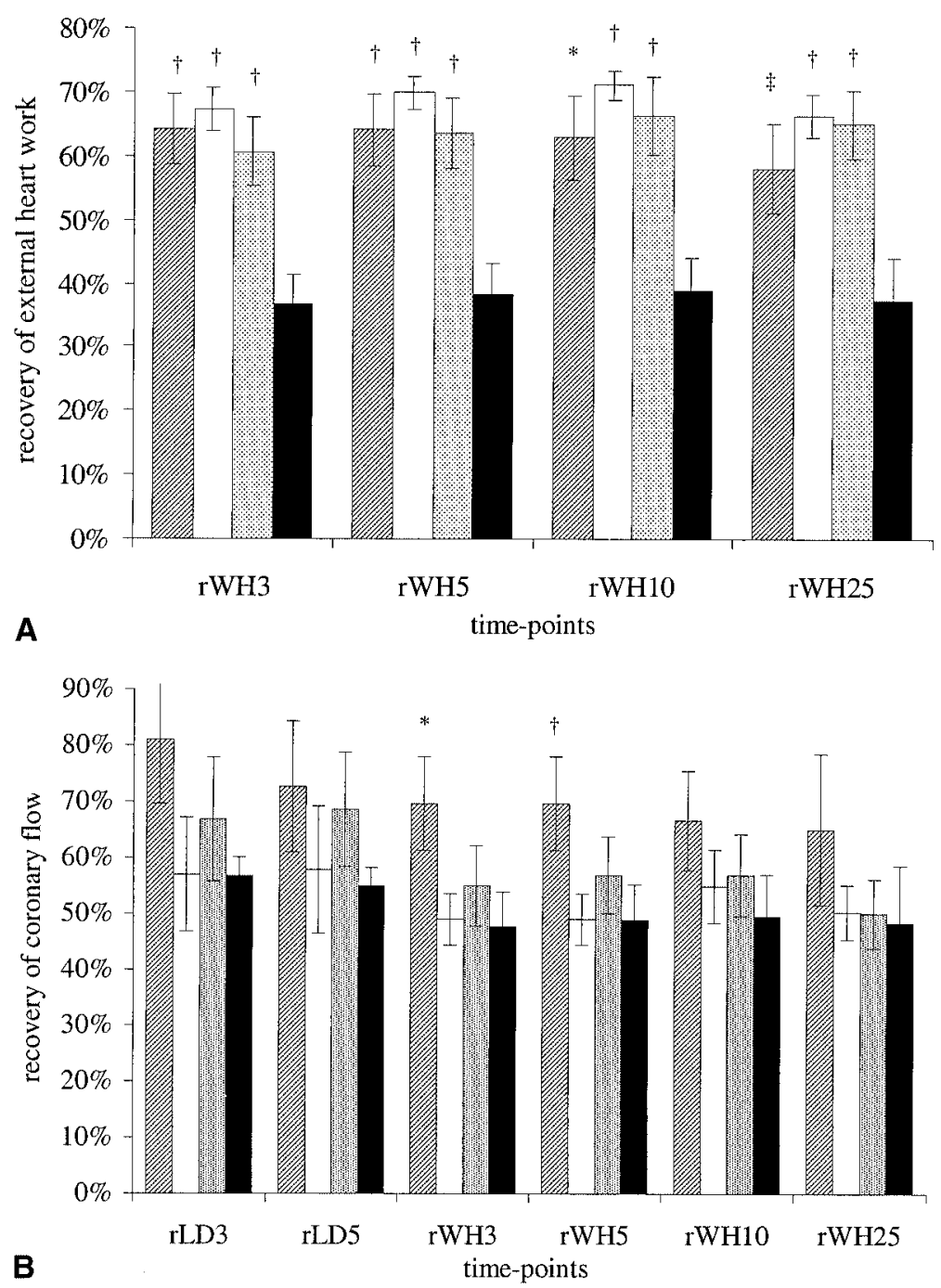

Figure 2. Postischemic recovery of hemodynamic parameters. Time points define time in minutes elapsed in Langendorff (rLD) and working-heart ( $r W H$ ) modes respectively during reperfusion; Recovery denotes percentage referenced to preischemic baseline. Bar heights represent mean; error bars represent SEM. Diagonally filled bars, Ischemia quinaprilat group; white bars, reperfusion quinaprilat group; dotted bars, arginine group; black bars, control group. A. External heart work. Asterisk indicates $P<.01$; dagger indicates $P<.001$; double dagger indicates $P=.012$. B. Coronary flow. Asterisk indicates $P=.018$ vs control group and $P=.029$ vs reperfusion quinaprilat group; dagger indicates $P=.023$ vs control group and $P=.028$ vs reperfusion quinaprilat group.

sumed sinus rhythm with adequate heart rate (ischemia quinaprilat group $196 \pm 17$ beats/min, reperfusion quinaprilat group $197 \pm 9$ beats/min, arginine group $205 \pm 5$ beats/min, and control group $186 \pm 8$ beats/min).

The postischemic myocardial function was markedly improved in all treatment groups, with substantially elevated cardiac output (mean recoveries in ischemia quinaprilat group $68 \% \pm 5 \%, P<.001$ vs control group, reperfusion quinaprilat group $76 \% \pm 3 \%, P<.001$ vs control group, and arginine group $66 \% \pm 5 \%, P=.001$ vs control group) relative to the control group $(43 \% \pm 5 \%)$. These differences were paralleled in the external heart work (mean recoveries in ischemia quinaprilat group $62 \% \pm 6 \%, P=.001$ vs control group, reperfusion quinaprilat group $69 \% \pm 3 \%$, $P<.001$ vs control group, arginine group $64 \% \pm 5 \%, P<$ .001 vs control group, and control group 35\% $\pm 5 \%$; Figure $2, A$ ). The recovery of external stroke work (mean recoveries in ischemia quinaprilat group $67 \% \pm 4 \%, P<.001$ vs control group, reperfusion quinaprilat group $71 \% \pm 3 \%, P<.001$ vs control group, arginine group $67 \% \pm 4 \%, P=.001$ vs control group, and control group $44 \% \pm 5 \%$ ) confirmed the marked improvement in myocardial function and stroke volume, because differences in heart rate were only minor.

Coronary flow during reperfusion was diminished in all 
TABLE 1. Myocardial oxygen consumption

\begin{tabular}{lccc}
\hline Group & $\begin{array}{c}\text { Baseline } \\
\left(\mathbf{m L} \cdot \mathbf{m i n}^{-1} \cdot \mathbf{g}^{-1}\right)\end{array}$ & $\begin{array}{c}\text { Reperfusion } \\
\left(\mathbf{m L} \cdot \mathbf{m i n}^{-1} \cdot \mathbf{g}^{-1}\right)\end{array}$ & $\begin{array}{c}\text { Recovery } \\
(\%)\end{array}$ \\
\hline $\begin{array}{l}\text { Ischemia } \\
\text { quinaprilat group }\end{array}$ & $7.6 \pm 0.9$ & $4.6 \pm 1.2$ & $68 \% \pm 19 \%$ \\
$\begin{array}{l}\text { Reperfusion } \\
\quad \text { quinaprilat group }\end{array}$ & $6.8 \pm 2.3$ & $6.4 \pm 2.9$ & $91 \% \pm 26 \%$ \\
$\begin{array}{l}\text { Arginine group } \\
\text { Control group }\end{array}$ & $7.6 \pm 1.0$ & $4.7 \pm 1.6$ & $56 \% \pm 14 \%$ \\
& $7.2 \pm 1.7$ & $4.2 \pm 0.8$ & $65 \% \pm 12 \%$
\end{tabular}

Data are expressed as mean \pm SEM. Baseline and reperfusion readings were obtained at 10 minutes of the preischemic working-heart mode and 10 minutes of the postischemic working-heart mode, respectively.

groups (mean recoveries in ischemia quinaprilat group 68\% $\pm 9 \%$, reperfusion quinaprilat group $51 \% \pm 5 \%$, arginine group 55\% $\pm 7 \%$, and control group $49 \% \pm 7 \%$ ); however, recovery was significantly different among groups (overall $P=.011$ by ANOVA with multiple adjustments of TukeyKramer). When quinaprilat was administered during ischemia, the recovery of coronary flow was substantially improved relative to both postischemic administration and control values. These differences were most significant at 3 and 5 minutes after initiation of the postischemic workingheart period (eg, at 5 minutes, $P=.023$ vs control group and $P=.028$ vs reperfusion quinaprilat group; Figure $2, B$ ). Treatment with L-arginine did not yield significant improvement. Analysis of the postischemic time course revealed a rising trend toward the end of the experiment in the reperfusion quinaprilat group relative to other groups.

\section{Biochemical Data}

There were no significant differences in preischemic myocardial oxygen consumption. During reperfusion, mean oxygen consumption decreased in all groups (Table 1). Considering the correlation of oxygen consumption with the actual cardiac work $(r=0.437)$, the postischemic levels in treatment groups, especially the ischemia quinaprilat and arginine groups, appeared relatively low. Because of wide variations of individual readings, an analysis of covariance including the external heart work as covariable did not show any differences to be significant $(P>.2)$. Measurement of nitrate and nitrite in the perfusion fluid at baseline (ischemia quinaprilat group $16.6 \pm 1.1 \mu \mathrm{mol} \cdot \mathrm{L}^{-1}$, reperfusion quinaprilat group $15.5 \pm 4.2 \mu \mathrm{mol} \cdot \mathrm{L}^{-1}$, arginine group $12.6 \pm 2.6 \mu \mathrm{mol} \cdot \mathrm{L}^{-1}$, and control group $19.8 \pm 3.3 \mu \mathrm{mol}$ $\cdot \mathrm{L}^{-1}$ ) as well as after reperfusion (ischemia quinaprilat group $18.6 \pm 1.3 \mu \mathrm{mol} \cdot \mathrm{L}^{-1}$, reperfusion quinaprilat group $15.6 \pm 4.3 \mu \mathrm{mol} \cdot \mathrm{L}^{-1}$, arginine group $13.5 \pm 1.7 \mu \mathrm{mol} \cdot$ $\mathrm{L}^{-1}$, and control group $22.8 \pm 4.0 \mu \mathrm{mol} \cdot \mathrm{L}^{-1}$ ) showed no significant differences in accumulation of these metabolites.

Mean levels of ATP and CP were consistently elevated in all treatment groups relative to control levels. Significant differences in the ischemia quinaprilat group were seen in both ATP concentrations (ischemia quinaprilat group
TABLE 2. Ultrastructural results

\begin{tabular}{lcccc}
\hline & $\begin{array}{c}\text { Ischemia } \\
\text { quinaprilat } \\
\text { group }\end{array}$ & $\begin{array}{c}\text { Reperfusion } \\
\text { quinaprilat } \\
\text { group }\end{array}$ & $\begin{array}{c}\text { Arginine } \\
\text { group }\end{array}$ & $\begin{array}{c}\text { Control } \\
\text { group }\end{array}$ \\
\hline $\begin{array}{l}\text { Total microscopic } \\
\text { fields assessed }\end{array}$ & 15 & 15 & 18 & 21 \\
Grade 0 & $100 \%$ & $47 \%$ & $55 \%$ & $24 \%$ \\
Grade 1 & $0 \%$ & $47 \%$ & $39 \%$ & $28 \%$ \\
Grade 2 & $0 \%$ & $6 \%$ & $6 \%$ & $48 \%$ \\
$P$ value vs control & .001 & .053 & .048 & - \\
$\quad$ group & & & & \\
\hline
\end{tabular}

Percentile distribution of grades of postischemic mitochondrial damage, with grades as defined in text.

$2.24 \pm 0.14 \mu \mathrm{mol} \cdot \mathrm{g}^{-1}, P=.040$ vs control group, reperfusion quinaprilat group $2.12 \pm 0.21 \mu \mathrm{mol} \cdot \mathrm{g}^{-1}$, arginine group $1.83 \pm 0.15 \mu \mathrm{mol} \cdot \mathrm{g}^{-1}$, and control group $1.81 \pm 0.12 \mu \mathrm{mol} \cdot \mathrm{g}^{-1}$ ) and $\mathrm{CP}$ concentrations (ischemia quinaprilat group $3.34 \pm 0.31 \mu \mathrm{mol} \cdot \mathrm{g}^{-1}, P=.056 \mathrm{vs}$ control group, reperfusion quinaprilat group $2.71 \pm 0.48$ $\mu \mathrm{mol} \cdot \mathrm{g}^{-1}$, arginine group, $2.73 \pm 0.28 \mu \mathrm{mol} \cdot \mathrm{g}^{-1}$, and control group, $2.50 \pm 0.27 \mu \mathrm{mol} \cdot \mathrm{g}^{-1}$ ).

\section{Ultrastructural Data}

Treatment groups showed preservation of mitochondrial integrity superior to that of the control group $(P=.006$ by ANOVA; Table 2). Most significant results were observed in the ischemia quinaprilat group (no visible damage in all hearts, $P=.001$ vs control group). Likewise the minor grade mitochondrial damages observed in the reperfusion quinaprilat and arginine groups constituted notable improvement over the control group $(P=.053$ and $P=.048$, respectively). Representative photomicrographs of mitochondrial damages are depicted in Figure 3. Overall, the assessment by two independent observers yielded a concordance rate of $95 \%$; discordant findings $(n=5 / 105)$ were quoted according to the higher grade.

\section{Discussion}

Experimental study always raises a question about the validity of clinical conclusions extrapolated from the results. In organ preparations, the artificial isolation from intervening systemic influences constitutes the primary limiting factor. The lack of platelets, leukocytes, and inflammatory cytokines has to be taken into account. However, cardioplegic arrest as a paradigm for global ischemia-reperfusion injury with comparable separation of the heart from systemic variables lends itself to studies on the isolated heart. This model offers major advantages, in particular by demonstrating pharmacologic effects at the organ level. Use of the working-heart perfusion mode and an erythrocytecontaining perfusate provides a closer approach to in vivo conditions. The addition of red blood cells to the more commonly used crystalloid perfusion fluid not only affords 

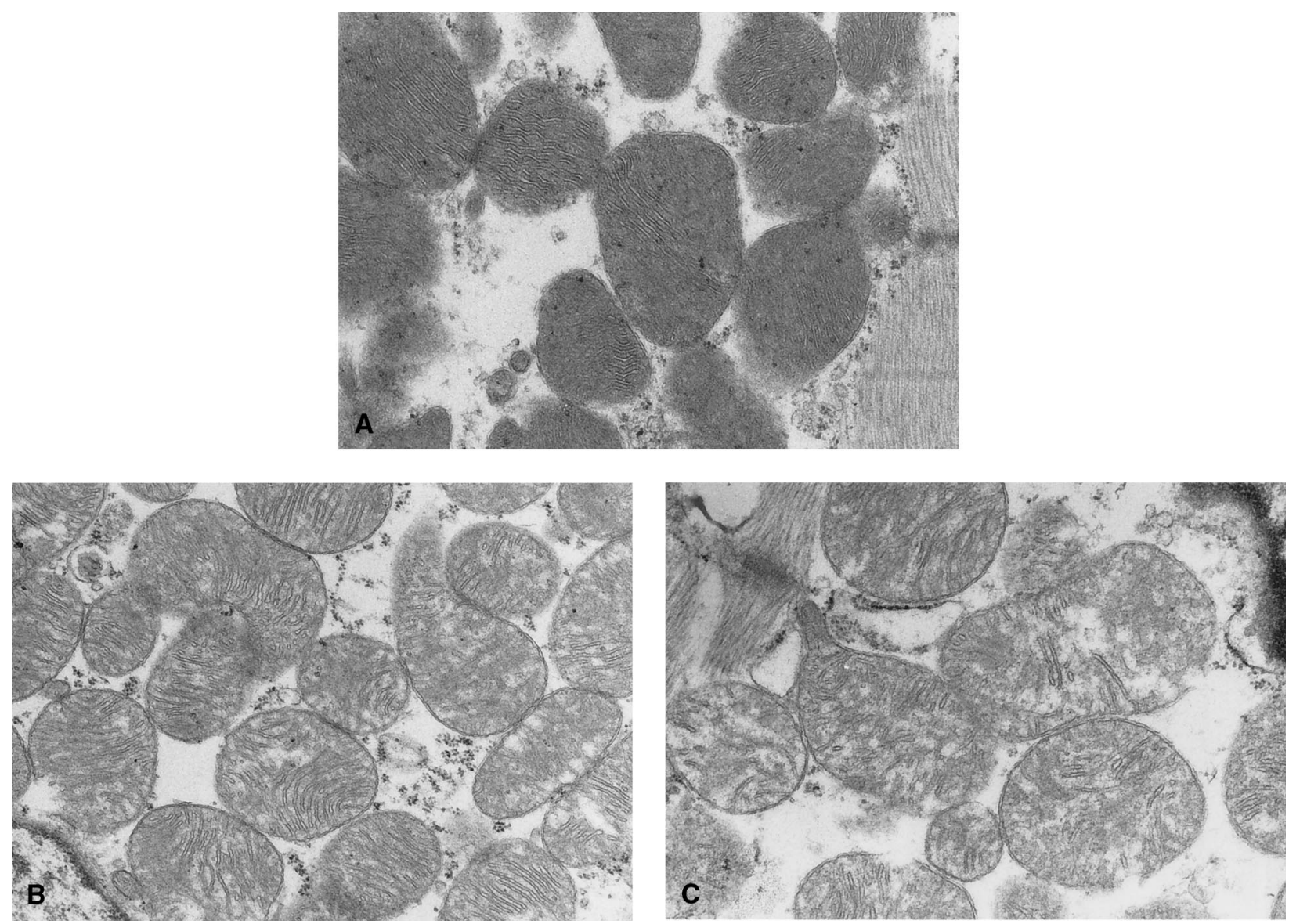

Figure 3. Mitochondrial ultrastructure. Representative photomicrographs (original magnification $\times 45,000$ ) depicting range of observed postischemic damages; grading as defined in text. A, No discernable damage (grade 0 ). B, Light clearing of matrix with loss of granules (grade 1). C, Additional swelling and partial fragmentation of cristae (grade 2).

oxygen-carrying capacity and coronary flow autoregulation within the physiologic range, ${ }^{20}$ it also provides crucial biochemical functions, such as buffering of oxygen radicals and catabolism of nitric oxide.

In our experiment, inhibition of intracardiac ACE and kininase II during either ischemia or reperfusion was followed by markedly improved recovery of myocardial function relative to control hearts. Treatment with L-arginine was associated with similar improvement. Quinaprilat and L-arginine do not convey direct positive inotropic effects, so the superior myocardial function seems to result from heightened prevention of myocardial ischemia-reperfusion damage. Two groups have obtained comparable results with isolated rat heart preparations, although both perfused the hearts with Krebs-Henseleit buffer in Langendorff mode and subjected them to warm cardioplegic arrest. Menasche and associates ${ }^{10}$ tested the effects of advance treatment ( 48 hours) with either captopril or enalapril. Gurevitch and colleagues ${ }^{11}$ administered captopril during either cardioplegia or reperfusion. Both observed improvements in coro- nary flow and myocardial recovery. However, the limitations of crystalloid perfusion fluid and the Langendorff mode have to be taken into account when extrapolating these results to in vivo conditions. ${ }^{13,20}$ Lazar and coworkers, ${ }^{12}$ in a porcine model with regional ischemia followed by acute surgical revascularization, showed beneficial effects of systemic enalaprilat administered before cardioplegic arrest. A reduction in infarct size, less myocardial irritability, and superior wall motion were noted.

The beneficial effects of L-arginine on myocardial recovery after cardioplegic arrest were confirmed in several studies. By adding L-arginine to blood cardioplegic solution, Mizuno and colleagues ${ }^{21}$ reversed endothelial dysfunction and improved myocyte recovery after reperfusion in a porcine model. Amrani and coworkers ${ }^{22}$ concluded that administration during reperfusion provided improved recovery after moderate $\left(20^{\circ} \mathrm{C}\right)$ and deep $\left(4^{\circ} \mathrm{C}\right)$ hypothermia, whereas only moderate hypothermia was amenable to coadministration during cardioplegia. A recent phase I pilot study tested the effects of L-arginine administered during the first 30 
minutes of cardioplegia on patients undergoing coronary artery bypass grafting. Although the safety was established, the release of troponin I was not shown to be reduced after administration of L-arginine. ${ }^{23}$

A direct biochemical characterization of the underlying mediators was not obtained with our working-heart apparatus. Our analysis showed that baseline concentrations of nitrate and nitrite in the perfusate were too high to assess small differences in nitric oxide production of the coronary endothelium through nitrate and nitrite determination in the perfusate. This situation is similar to in vivo conditions. Only dramatic increases in nitric oxide production (eg, in septic shock) are reflected by higher concentrations of nitrate and nitrite in the plasma. ${ }^{24}$ However, secondary mediators of ACE inhibition have been well established in the literature. Linz and colleagues ${ }^{3}$ elucidated the mediation by bradykinin and nitric oxide by using their respective inhibitors. Likewise, Kitakaze and coworkers ${ }^{4}$ demonstrated an equal blunting of ACE inhibitor-induced effects with either HOE 140 or $N$-nitro-L-arginine methyl ester. When testing ramiprilat in isolated guinea pig hearts, Massoudy and coworkers ${ }^{5}$ attributed the improved outcome to nitric oxidemediated effects. In particular, various cyclic guanosine monophosphate-independent effects of nitric oxide seem to be crucial for the cardioprotection. The avid annihilation of oxygen radicals suggests significant scavenger activity during ischemia-reperfusion. ${ }^{5,25,26}$ Recently, alteration of enzyme activities by binding of nitric oxide to heme prosthetic groups and iron-sulfur centers has received increasing attention. The comparable myocardial recoveries seen with quinaprilat and L-arginine in our study were consistent with these findings from the literature. Because no additional benefits of ACE inhibitors over L-arginine in terms of myocardial protection were seen, the induction of nitric oxide synthesis alone may be as effective as ACE inhibition.

The myocardial metabolism has to be discussed with respect to the underlying differences in postischemic myocardial work. In light of the markedly increased postischemic cardiac work, the trend toward relatively lower oxygen consumption that we observed, especially in the ischemia quinaprilat and arginine groups, was in keeping with recent evidence of reduction in oxygen consumption by means of ACE inhibitors. Zhang and coworkers ${ }^{27}$ described this effect after the application of ACE inhibitors to myocardial tissue preparations and proved that it is mediated by the bradykinin-nitric oxide axis. However, the high variability of oxygen consumption in our isolated heart model precludes further conclusions.

Analysis of high-energy phosphates at the end of our experimental protocol provided postischemic steady-state levels, as determined by both synthesis and expenditure. Both superior preservation of mitochondrial oxidative phosphorylation and prevention of the inadequate expenditure of high-energy compounds precipitated by ischemia-reperfusion damage may account for these results. Additionally, a direct drug effect, such as the assumed inhibition of enzymes in the respiratory chain by nitric oxide, ${ }^{27}$ might also be involved. Comparable studies in the literature confirm favorable preservation of high-energy phosphates, especially with early initiation of ACE inhibition. Cargnoni and coworkers $^{1}$ demonstrated higher recoveries of ATP and CP after global ischemia and reperfusion in isolated rabbit hearts treated in advance with quinaprilat. Zhu and colleagues ${ }^{28}$ found that superior myocardial recovery after bradykinin administration was partially related to conservation of ATP and CP, which were only elevated when drug administration was initiated before ischemia.

The functional outcome indicated by high-energy phosphate levels is paralleled by markedly improved preservation of mitochondrial integrity. These data are of particular interest as they relate to the reduction of oxidative stress attributed to ACE inhibitors and nitric oxide. Because the ultrastructural alterations primarily represent membrane disruption caused by lipid peroxidation, they reflect the ultimate damaging potential of oxygen radicals. Thus their reduction provides indirect evidence of an antioxidant treatment effect. Various biochemical assays described in the literature confirm such a reduction in oxidative stress. Decreases in glutathione release and a lower fraction of its oxidized form have been associated with the improvement in myocardial recovery observed after ACE inhibition. ${ }^{1,5}$ The ability of nitric oxide donors to reduce oxidative stress was confirmed by means of chemiluminescence. ${ }^{5}$ Quinaprilat, a carboxyl-type ACE inhibitor, lacks the intrinsic antioxidant property often ascribed to sulfhydryl-containing compounds (eg, captopril). ${ }^{10}$ Thus our results must be attributable to alterations of the mediator profile, most likely the increase of nitric oxide or reduction of angiotensin II.

The recovery of coronary flow was significantly improved when quinaprilat was administered during ischemia, whereas quinaprilat given during reperfusion and $\mathrm{L}$-arginine both showed no substantial effect. These findings, in accordance with the literature, may be explained by improved vascular autoregulation by means of preserved endothelial function or a direct vasodilatory effect.

The lack of significant vasodilation with postischemic administration argues against a direct vasodilatory drug effect and suggests a protective effect on vasomotor function when ACE inhibition is initiated during ischemia. This hypothesis was supported in two experiments with porcine models, one in which ACE inhibitors were administered during short-term ischemia ${ }^{29}$ and another in which L-arginine was added to blood cardioplegia. ${ }^{21}$ Both demonstrated postischemic reductions of endothelium-dependent vasodilation, which were reversed by the respective treatment modalities. Recent evidence that angiotensin II contributes 
to oxidative vascular injury by inducing generation of superoxide anions in smooth muscle cells through reduced nicotinamide adenine dinucleotide oxidase activation ${ }^{30,31}$ may account for additional protection with ACE inhibition relative to L-arginine. Improved vascular protection is of particular interest, because standard potassium cardioplegia is designed primarily for myocardial preservation, ${ }^{32}$ and the relatively unprotected vascular structures, especially endothelial cells, appear to be highly susceptible to ischemic damage. ${ }^{21,33,34}$ It has been observed that endothelial injury is an early event during cardioplegic arrest, and functional disturbance (diminished release of nitric oxide) has been seen immediately at the beginning of reperfusion ${ }^{21}$; this emphasizes the significance of early drug administration to prevent endothelial stunning. Furthermore, vasomotor dysfunction has been described as an untoward effect of depolarizing cardioplegic solutions. ${ }^{21,33,35}$ Aside from dysfunctional intrinsic regulation of vascular tone, the postischemic coronary flow may also be compromised by insufficient coronary reserve or extrinsic compressive forces related to edema. These forces are in part determined by the state of the endothelium. However, some aspects related to the experimental model need to be heeded in this context. Increased edema and diminished coronary reserve are commonly seen in crystalloid-perfused hearts; in our model, this was avoided by using an erythrocyte-based perfusate. ${ }^{13}$ The lack of inflammatory mediators, however, needs to be taken into account.

Alternatively, one might reason that ACE inhibition has a direct vasodilatory effect with a latency period. The need for early ACE inhibition could be explained by ongoing angiotensin II-mediated vasoconstriction after initiation of ACE inhibition, related to a prolonged elimination half-life of angiotensin II in interstitial tissue. ${ }^{36}$ In support of this hypothesis is the poorer response in coronary flow seen in the reperfusion quinaprilat and arginine groups, as well as the rising trend toward the end of the reperfusion period seen in the ischemia quinaprilat group. The superior vasodilation observed with early ACE inhibition might be due to the delayed reduction of angiotensin II constrictor activity, whereas myocardial protection could be mediated primarily by the rapidly adjusting bradykinin-nitric oxide system. Experiments with selective inhibitors of the angiotensin II type 1 receptor (CV11974, losartan) showed inconclusive results concerning the effect of angiotensin II on coronary flow, ${ }^{4,37}$ and a biochemical confirmation of this hypothesis is necessary.

Individual pharmacodynamic properties of different types of ACE inhibitor must also be considered. A recent study that compared the abilities of ACE inhibitors to enhance endothelium-dependent vasodilation in the radial artery revealed an increased responsiveness with quinaprilat relative to enalaprilat, which showed no effect relative to control. ${ }^{37}$ This difference, explained by the higher affinity of quinaprilat for tissue ACE, ${ }^{38}$ might also account for the improved coronary flow preservation in our study, which was not seen in the previously mentioned experiment by Lazar and colleagues. ${ }^{12}$

In conclusion, quinaprilat administration during cold blood cardioplegia provides a promising approach for improving both myocardial protection and postischemic coronary flow. In this isolated rabbit heart model, postischemic hemodynamics, myocardial energy status, and ultrastructural morphologic characteristics were consistently improved when treatment was initiated during ischemia.

\section{References}

1. Cargnoni A, Boraso A, Scotti C, Ghirardelli N, Benigno M, Bernocchi $\mathrm{P}$, et al. Effect of angiotensin converting enzyme inhibition with quinaprilat on the ischaemic and reperfused myocardium. J Mol Cell Cardiol. 1994;26:69-86.

2. Ehring T, Baumgart D, Krajcar M, Hummelgen M, Kompa S, Heusch G. Attenuation of myocardial stunning by the ACE inhibitor ramiprilat through a signal cascade of bradykinin and prostaglandins but not nitric oxide. Circulation. 1994;90:1368-85.

3. Linz W, Wiemer G, Scholkens BA. ACE-inhibition induces NOformation in cultured bovine endothelial cells and protects isolated ischemic rat hearts. J Mol Cell Cardiol. 1992;24:909-19.

4. Kitakaze M, Minamino T, Node K, Komamura K, Shinozaki Y, Mori $\mathrm{H}$, et al. Beneficial effects of inhibition of angiotensin-converting enzyme on ischemic myocardium during coronary hypoperfusion in dogs. Circulation. 1995;92:950-61.

5. Massoudy P, Becker BF, Gerlach E. Nitric oxide accounts for postischemic cardioprotection resulting from angiotensin-converting enzyme inhibition: indirect evidence for a radical scavenger effect in isolated guinea pig heart. J Cardiovasc Pharmacol. 1995;25:440-7.

6. van Gilst WH, Kingma JH, Peels KH, Dambrink JH, St John Sutton $\mathrm{M}$. Which patient benefits from early angiotensin-converting enzyme inhibition after myocardial infarction? Results of one-year serial echocardiographic follow-up from the Captopril and Thrombolysis Study (CATS). J Am Coll Cardiol. 1996;28:114-21.

7. ISIS-4 (Fourth International Study of Infarct Survival) Collaborative Group. ISIS-4: a randomised factorial trial assessing early oral captopril, oral mononitrate, and intravenous magnesium sulphate in 58,050 patients with suspected acute myocardial infarction. Lancet. 1995;345:669-85.

8. Ambrosioni E, Borghi C, Magnani B. The effect of the angiotensinconverting-enzyme inhibitor zofenopril on mortality and morbidity after anterior myocardial infarction. The Survival of Myocardial Infarction Long-Term Evaluation (SMILE) Study Investigators. $N$ Engl J Med. 1995;332:80-5.

9. The GISSI-3 APPI Study Group. Early and six-month outcome in patients with angina pectoris early after acute myocardial infarction (the GISSI-3 APPI [angina precoce post-infarto] study). Am J Cardiol. 1996;78:1191-7.

10. Menasche P, Grousset C, Peynet J, Mouas C, Bloch G, Piwnica A. Pretreatment with captopril improves myocardial recovery after cardioplegic arrest. J Cardiovasc Pharmacol. 1992;19:402-7.

11. Gurevitch J, Pevni D, Frolkis I, Matsa M, Paz Y, Mohr R, et al. Captopril in cardioplegia and reperfusion: protective effects on the ischemic heart. Ann Thorac Surg. 1997;63:627-33.

12. Lazar HL, Volpe C, Bao Y, Rivers S, Vita JA, Keaney JF Jr. Beneficial effects of angiotensin-converting enzyme inhibitors during acute revascularization. Ann Thorac Surg. 1998;66:487-92.

13. Podesser B, Hallström S, Schima H, Huber L, Weisser J, Kröner A, et al. The erythrocyte perfused "working heart" model: hemodynamic and metabolic performance in comparison to crystalloid perfused hearts. J Pharmacol Toxicol Methods. 1999;41:9-15. 
14. Podesser B, Hausleithner V, Seitelberger R, Wollenek G, Wolner E, Steiert H. New developments in the isolated working heart: a comparison of neonatal, immature, and adult rabbits after sixty minutes of ischemia in respect to hemodynamic and biochemical parameters. J Pharmacol Toxicol Methods. 1993;30:189-96.

15. Jackson E, Garrison C. Renin and angiotensin. In: Hardman JG, Limbird LE, editors. Goodman and Gilman's the pharmacological basis of therapeutics. 9th ed. New York: McGraw-Hill; 1996. p. 733-58.

16. Plosker GL, Sorkin EM. Quinapril: a reappraisal of its pharmacology and therapeutic efficacy in cardiovascular disorders. Drugs. 1994;48: 227-52.

17. Green LC, Wagner DA, Glogowski J, Skipper PL, Wishnok JS, Tannenbaum SR. Analysis of nitrate and $\left({ }^{15} \mathrm{~N}\right)$ nitrate in biological fluids. Anal Biochem. 1982;126:131-8.

18. Fürst W, Hallström S. Simultaneous determination of myocardial nucleotides, nucleosides, purine bases and creatine phosphate by ionpair high-performance liquid chromatography. J Chromatogr. 1992; 578:39-44.

19. Schaper J, Mulch J, Winkler B, Schaper W. Ultrastructural, functional, and biochemical criteria for estimation of reversibility of ischemic injury: a study on the effects of global ischemia on the isolated dog heart. J Mol Cell Cardiol. 1979;11:521-41.

20. Deng Q, Scicli AG, Lawton C, Silverman NA. Coronary flow reserve after ischemia and reperfusion of the isolated heart: divergent results with crystalloid versus blood perfusion. J Thorac Cardiovasc Surg. 1995;109:466-72.

21. Mizuno A, Baretti R, Buckberg GD, Young HH, Vinten-Johansen J, Ma XL, et al. Endothelial stunning and myocyte recovery after reperfusion of jeopardized muscle: a role of L-arginine blood cardioplegia. J Thorac Cardiovasc Surg. 1997;113:379-89.

22. Amrani M, Gray CC, Smolenski RT, Goodwin AT, London A, Yacoub $\mathrm{MH}$. The effect of L-arginine on myocardial recovery after cardioplegic arrest and ischemia under moderate and deep hypothermia. Circulation. 1997;96(9 suppl 2):II274-9.

23. Carrier M, Pellerin M, Page PL, Searle NR, Martineau R, Caron C, et al. Can L-arginine improve myocardial protection during cardioplegic arrest? Results of a phase I pilot study. Ann Thorac Surg. 1998;66: 108-12.

24. Ochoa JB, Udekwu AO, Billiar TR, Curran RD, Cerra FB, Simmons RL, Peitzman AB. Nitrogen oxide levels in patients after trauma and during sepsis. Ann Surg. 1991;214:621-6.

25. Maulik N, Engelman DT, Watanabe M, Engelman RM, Maulik G, Cordis GA, et al. Nitric oxide signaling in ischemic heart. Cardiovasc Res. 1995;30:593-601.
26. Nakanishi K, Zhao ZQ, Vinten-Johansen J, Hudspeth DA, McGee DS, Hammon JW Jr. Blood cardioplegia enhanced with nitric oxide donor SPM-5185 counteracts postischemic endothelial and ventricular dysfunction. J Thorac Cardiovasc Surg. 1995;109:1146-54.

27. Zhang X, Xie YW, Nasjletti A, Xu X, Wolin MS, Hintze TH. ACE inhibitors promote nitric oxide accumulation to modulate myocardial oxygen consumption. Circulation. 1997;95:176-82.

28. Zhu P, Zaugg CE, Simper D, Hornstein P, Allegrini PR, Buser PT. Bradykinin improves postischaemic recovery in the rat heart: role of high energy phosphates, nitric oxide, and prostacyclin. Cardiovasc Res. 1995;29:658-63.

29. Piana RN, Wang SY, Friedman M, Sellke FW. Angiotensin-converting enzyme inhibition preserves endothelium-dependent coronary microvascular responses during short-term ischemia-reperfusion. Circulation. 1996;93:544-51.

30. Griendling KK, Minieri CA, Ollerenshaw JD, Alexander RW. Angiotensin II stimulates NADH and NADPH oxidase activity in cultured vascular smooth muscle cells. Circ Res. 1994;74:1141-8.

31. Rajagopalan S, Kurz S, Munzel T, Tarpey M, Freeman BA, Griendling KK, et al. Angiotensin II-mediated hypertension in the rat increases vascular superoxide production via membrane NADH/ NADPH oxidase activation: contribution to alterations of vasomotor tone. J Clin Invest. 1996;97:1916-23.

32. Cordell AR. Milestones in the development of cardioplegia. Ann Thorac Surg. 1995;60:793-6.

33. Sellke FW, Shafique T, Schoen FJ, Weintraub RM. Impaired endothelium-dependent coronary microvascular relaxation after cold potassium cardioplegia and reperfusion. J Thorac Cardiovasc Surg. 1993;105:52-8.

34. Dignan RJ, Kadletz M, Dyke CM, Lutz HA, Yeh T Jr, Wechsler AS. Microvascular dysfunction after myocardial ischemia. J Thorac Cardiovasc Surg. 1995;109:892-7.

35. He GW, Yang CQ. Superiority of hyperpolarizing to depolarizing cardioplegia in protection of coronary endothelial function. J Thorac Cardiovasc Surg. 1997;114:643-50.

36. van-Kats JP, de-Lannoy LM, Jan-Danser AH, van-Meegen JR, Verdouw PD, Schalekamp MA. Angiotensin II type 1 (AT1) receptormediated accumulation of angiotensin II in tissues and its intracellular half-life in vivo. Hypertension. 1997;30:42-9.

37. Werrmann JG, Cohen SM. Use of losartan to examine the role of the cardiac renin-angiotensin system in myocardial dysfunction during ischemia and reperfusion. J Cardiovasc Pharmacol. 1996;27:177-82.

38. Hornig B, Arakawa N, Haussmann D, Drexler H. Differential effects of quinaprilat and enalaprilat on endothelial function of conduit arteries in patients with chronic heart failure. Circulation. 1998;98:2842-8. 